\title{
Treatment of the Ear Giant Keratoacanthoma with Topical Imiquimod
}

\author{
${ }^{1}$ Department of Dermatology, Xiang'an Hospital of Xiamen University, Xiamen, China \\ ${ }^{2}$ Department of nursing, Xiang'an Hospital of Xiamen University, Xiamen, China \\ ${ }^{3}$ Department of Dermatology, Tianjin Medical University General Hospital, Tianjin, China \\ ${ }^{4}$ Thyroid breast surgery, Xiang'an Hospital of Xiamen University, Xiamen, China \\ ${ }^{5}$ Ackerman Academy of Dermatopathology, New York, NY \\ ${ }^{6}$ Department of Dermatology, No.1 Hospital of China Medical University, Shenyang, China
}

Shi-Jun Shan ${ }^{1}$, Jiwei Du², Wanxing Zhang ${ }^{3}$, Guojun Zhang", Ying Guo ${ }^{5}$, Hong-Duo Chen ${ }^{1,6}$

Submission: April 28, 2018; Published: June 12, 2018

*Corresponding author: Chen, Department of Dermatology, Xiang'an Hospital of Xiamen University, No. 2000, Xiang'an East Road, Xiamen, 361102 , China Chen, Department of Dermatology, No.1 Hospital of China Medical University, 155 North Nanjing Street, Shenyang 110001, China, Tel: +86-15822183620; Email: hongduochen@hotmil.com

\begin{abstract}
Keratoacanthoma (KA) is an epidermal neoplasma with rapid growth and severe local destruction. Owing to its similarities to squamous cell carcinoma, complete surgical excision is mainly recommended. Topical imiquimod is an ideal option for the problematic sites and cosmetic demands. Here we report a giant case of KA on a rare anatomical location, and fully recorded the disease process. The patient was treated successfully with topical imiquimod.

Keywords: Keratoacanthoma; Imiquimod

What's already known about this topic?

Keratoacanthoma (KA) is an epidermal neoplasma with rapid growth and local destruction. Topical imiquimod is an ideal option for the problematic sites and cosmetic demands.

\section{What does this study add?}

- The patient presented with a giant KA lesions on the left anthelix, which was a rare anatomical location and not recorded in the medical literatures.

- The tumor process was fully described in our study.

- The tumor was successfully treated with topical imiquimod, which provides a valuable reference for the treatment of some malignant skin tumors with the topical immune regulatory therapy
\end{abstract}

\section{Introduction}

Keratoacanthoma (KA) is an epidermal neoplasma with rapid growth and spontaneous regression tendency. Owing to its similarities to squamous cell carcinoma (SCC) and severe local destruction, complete surgical excision is mainly recommended. However, nonsurgical options are required in consideration of the tumor size, problematic sites, and cosmetic demands [1,2]. Here, we report a giant KA case on the rare location successfully treated with topical imiquimod.

\section{Case Report}

A 87-year-old Chinese man presented to our clinic with rapidly growing large ear tumor for 6 months duration. The skin examination revealed a well-circumscribed, measuring about $3 \times 3 \mathrm{~cm}$, black-crusted crateriform tumor on the left ear. The lesion started as little papule with centre keratin plug suspect as virus wart, no treatment was given. The tumor rapidly grew to $3 \mathrm{~cm}$ in diameter; and the centre crust and ulceration with basis proliferation were observed at presentation (Figure1 A-D).

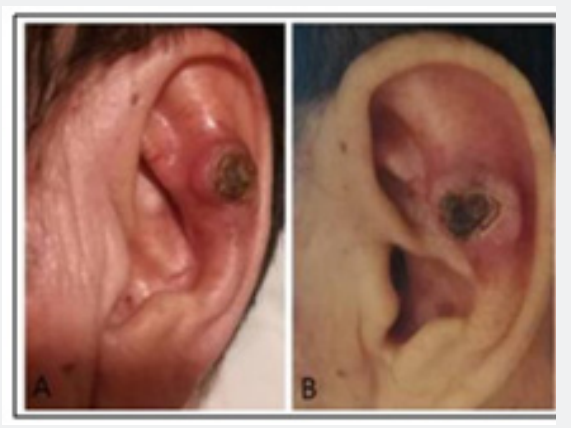

Figure 1A: At 4 weeks duration, a firm, rounded, flesh colure papule with raised margin and central keratin plug was observed.

Figure 1B: At 3 month's duration, rapidly evolving tumor showed central keratin filled crater and remarkable marginal proliferation. 


\section{Juniper Online Journal of Dermatology \& Cosmetics}

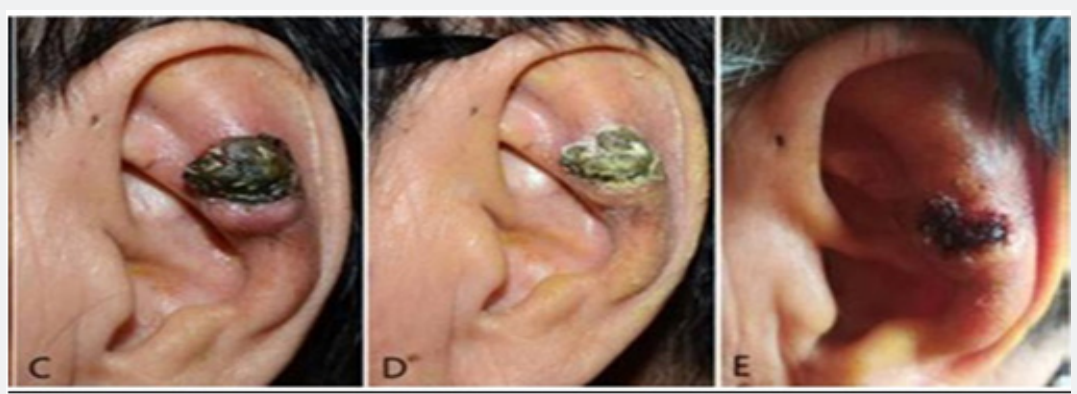

Figure 1C: The giant keratoacanthoma arising on the left anthelix with centre crust and basis sharply demarcated proliferation at presentation.

Figure 1D: Partial remission of the tumor after 6 weeks imiquimod treatment.

Figure 1E: The lesion regressed completely after 12 weeks with mild crust.

The previous history included prostate cancer and colon tumor with surgery treatment. Lab assay revealed mild decreased hemoglobins; hepatorenal functions were within normal limits. No enlarged superficial lymph node was palpable. Head-neck and thoracic computer tomography were carried out with negative results. Histopathological examination exhibited the regular crateriform architecture, with marked hyperkeratosis, acanthosis and papillomatosis; the atypia of squamous cells were found (Figure 2). The diagnosis of KA was confirmed. We treated him with the imiquimod cream once every 2 days. The tumor remarkably decreased in size after 6 week treatment. After 12 weeks, the lesion was almost completely cleared leaving mild crust. (Figure1E-F) Maintained treatment was applied for another 4 weeks.

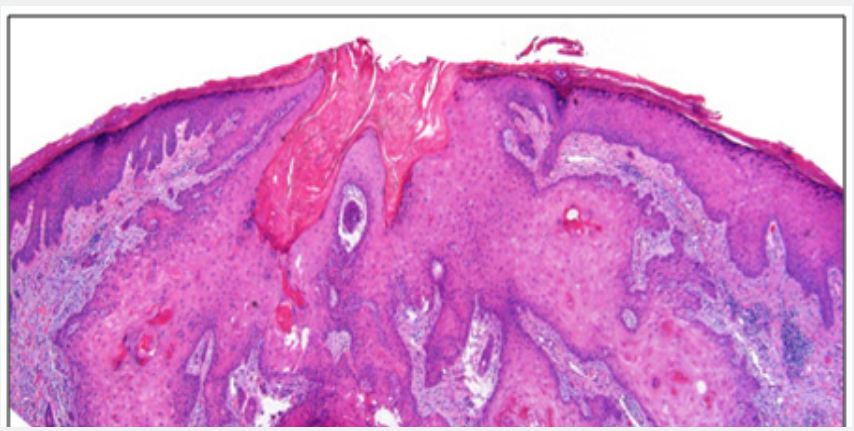

Figure 2: The lesion demonstrated the silhouette of KA: the regular crateriform architecture, with marked squamous cells proliferation and atypia. (hematoxylin-eosin stain, original magnification $\times 40$ )

\section{Discussion}

Keratoacanthoma (KA) is a benign epidermal neoplasma with local destruction. The aetiopathogenesis still remains uncertain. The complete process of the disease commonly lasts 4-9 months [2] KA is generally considered relevance to previous skin trauma, such as laser treatment and scars, and probably having relations to systemic immunosuppressive therapy [3-5]. Since the histological features of KA bears a close resemblance to typical SCC, and no befitting criterion can be used to distinguish with sufficient sensitivity and specificity, complete surgical excision was usually nominated for most cases [6]. However, surgery approach has its limitations. KA commonly grows on face and neck, oversized tumor and the problematic sites pose special difficulties for complete excision considering the cosmetic and functional need. When underlying malignancies have to be taken into account, alternative therapies are broadly researched all along.

A research indicated that topical imiquimod cream, topical 5-fluorouracil, intralesional 5FU, intralesional methotrexate, intralesional bleomycin, and intralesional interferon all showed high clearance rates when applied in KA [1] Among them topical imiquimod (once daily, 3 to 4 days per week, 12 weeks duration) even showed $100 \%$ clearance rate in the treatment of KA. Previous reports proved the same curative effects while applying topical imiquimod to KA lesions with the usage above $[7,8]$. Imiquimod, known as an immune-response modifier, can interact with Toll-like receptor 7 on antigen-presenting dendritic cells. After activating both the innate and acquired immune systems with the expression of varieties of cytokines, it can subsequently destruct tumor cells [9]. Along with therapeutic process, side effect as restricted severe inflammatory reactions seems unavoidable [7-10]. In our case, the tumor was located at the left anthelix, which was rare in previous reports. Considering the problematic anatomical location and tumor size, topical imiquimod was given. After about 12 -week treatment, the tumor was cleared. Another 4 weeks maintained treatment was given for the high risk of malignancy.

In summary, we report and add to the medical literature a unique case of giant keratoacanthoma of anthelix with fully recorded disease process, which was successfully treated with topical imiquimod. Our research provides a valuable reference for the treatment of some malignant skin tumors with the immunoregulatory therapy of topical imqumoid.

\section{References}

1. Chitwood K, Etzkorn J, Cohen G (2013) Topical and intralesional treatment of nonmelanoma skin cancer: efficacy and cost comparisons. Dermatol Surg 39(9): 1306-1316. 
2. Karaa A, Khachemoune A (2007) Keratoacanthoma: a tumor in search of a classification. Int J Dermatol 46(7): 671-678.

3. Pattee SF1, Silvis NG (2003) Keratoacanthoma developing in sites of previous trauma: a report of two cases and review of the literature. J Am Acad Dermatol 48(2 Suppl): S35-8.

4. Gewirtzman A1, Meirson DH, Rabinovitz H (1999) Eruptive keratoacanthomas following carbon dioxide laser resurfacing. Dermatol Surg 25(8): 666-668.

5. Dessoukey MW, Omar MF, Abdel-Dayem H (1997) Eruptive keratoacanthomas associated with immunosuppressive therapy in a patient with systemic lupus erythematosus. J Am Acad Dermatol 37(3 Pt 1): 478-480.

6. Schwartz RA (2004) Keratoacanthoma: a clinico-pathologic enigma. Dermatol Surg 30(2 Pt 2): 326-333.
7. Jeon HC, Choi M, Paik SH, Ahn CH, Park HS, et al. (2011) Treatment of keratoacanthoma with 5\% imiquimod cream and review of the previous report. Ann Dermatol 23(3): 357-361.

8. Rhee do Y, Won KH, Lee YJ, Won CH, Chang SE, et al. (2016) Successful treatment of multiple vemurafenib-induced keratoacanthomas by topical application of imiquimod cream: Confirmation of clinical clearance by dermoscopy. J Dermatolog Treat 27(5):448-449

9. Campalani E, Holden CA (2013) Keratoacanthoma associated with the use of topical imiquimod. Clin Exp Dermatol 38(5): 555-556.

10. Tsikeloudi M, Lallas A, Sidiropoulos T, Chasioti V, Lefaki I, et al. (2014) Imiquimod as neoadjuvant treatment for giant keratoacanthoma arising on a background of lupus vulgaris. Clin Exp Dermatol 39(1): 60-62.

\section{Your next submission with Juniper Publishers will reach you the below assets}

- Quality Editorial service

- Swift Peer Review

- Reprints availability

- E-prints Service

- Manuscript Podcast for convenient understanding

- Global attainment for your research

- Manuscript accessibility in different formats ( Pdf, E-pub, Full Text, Audio)

- Unceasing customer service

Track the below URL for one-step submission https://juniperpublishers.com/online-submission.php 